\title{
Narrative review of aplastic anemia-the importance of supportive treatment
}

\author{
Iwona Urbanowicz^, Wiesława Nahaczewska^, Beata Celuch \\ Department of Clinical Chemistry, Department of Hematology, Wroclaw Medical University, Wrocław, Poland \\ Contributions: (I) Conception and design: I Urbanowicz; (II) Administrative support: All authors; (III) Provision of study materials or patients: All \\ authors; (IV) Collection and assembly of data: W Nahaczewska; (V) Data analysis and interpretation: All authors; (VI) Manuscript writing: All \\ authors; (VII) Final approval of manuscript: All authors. \\ Correspondence to: Iwona Urbanowicz. Department of Clinical Chemistry, Department of Hematology, Wroclaw Medical University, Borowska 211A \\ Street, 50-556, Wrocław, Poland. Email: iwona.urbanowicz@umed.wroc.pl.
}

\begin{abstract}
Aplastic anemia (AA) is a rare, life-threatening syndrome of bone marrow failure resulted from bone marrow hypoplasia or aplasia, leading to pancytopenia (not only anemia). The most common cause is an autoimmune reaction of $\mathrm{T}$ lymphocytes against hematopoietic stem cells or, less frequently, a congenital defect or acquired damage to these cells, which leads to inhibition of their division and differentiation. AA can develop quickly (within a few days) or slowly (several weeks or months). The signs and symptoms are related to anemia, neutropenia, and thrombocytopenia. The concepts of treatment of patients with AA have significantly evolved in recent years. This is due to improved outcomes of both family and unrelated donor hematopoietic stem cell transplantations (HSCTs) as well as to revised results of immunosuppressive therapy (IST). The choice of the method depends essentially on three factors: the severity of AA, the age of the patient, matched sibling donor. All patients diagnosed with AA require appropriate supportive treatment adapted to the current clinical situation. Supportive treatment is necessary both before, during and after invasive causal treatment, it mainly involves the transfusion of leukocyte-depleted blood components, the use of anti-infectious prophylaxis or treatment of infections. In many cases AA, supportive therapy is the only therapeutic option, especially in elderly patients with comorbidities. In this paper we present current supportive treatment in this life-threatening disease.
\end{abstract}

Keywords: Aplastic anemia; clinical presentation; supportive treatment

Submitted May 28, 2020. Accepted for publication Nov 02, 2020.

doi: 10.21037/apm-20-1957

View this article at: http://dx.doi.org/10.21037/apm-20-1957

\section{Introduction}

Aplastic anemia (AA) is an acquired or congenital bone marrow failure in the production of all cell lines, without the presence of cancerous infiltrates and fibrosis, leading to pancytopenia. It is a disease that occurs rarely, however, it is fraught with serious prognosis in the absence of adequate treatment. With the development of effective therapies over the years, the prognosis has changed radically, mainly in young people with severe pancytopenia but results of specialist treatment are conditioned by appropriate supportive care.

The incidence in Europe and North America is estimated at 2-3 and 5-6 cases/million/year in Asia. AA can occur at any age, but most cases fall between $15-25$ years and over 60 years, without gender or race differences. Its etiology is not sufficiently understood $(1,2)$.

^ ORCID: Iwona Urbanowicz, 0000-0002-9489-322X; Wiesława Nahaczewska, 0000-0002-0356-9505. 
Table 1 Diagnostic criteria for AA based on the results of additional tests

\begin{tabular}{ll}
\hline Aplastic anemia (AA) & Hematological parameters \\
\hline Severe aplastic anemia (SAA) & $\begin{array}{l}\text { Bone marrow cellularity }<25 \% \text { or } 25-50 \% \text { with less than } 30 \% \text { residual hematopoietic } \\
\text { cells two of the three criteria below: neutrophils }<0.5 \times 10^{9} / \mathrm{L} ; \text { platelets }<20 \times 10^{9} / \mathrm{L} ; \\
\text { reticulocytes }<20 \times 10^{9} / \mathrm{L}\end{array}$ \\
Very severe aplastic anemia (VSAA) & $\begin{array}{l}\text { Similar to SAA, but neutrophils }<0.2 \times 10^{9} / \mathrm{L} \\
\text { Non-severe aplasic anemia (NSA) }\end{array}$ \\
& $\begin{array}{l}\text { Patients who do not meet the criteria for SAA and VSAA but with poor cell bone marrow, } \\
\text { who have two of three criteria: neutrophils }<1.5 \times 10^{9} / \mathrm{L} ; \text { platelets }<100 \times 10^{9} / \mathrm{L} ; \text { hemoglobin } \\
\text { concentration }<10 \mathrm{~g} / \mathrm{dL}\end{array}$ \\
\hline
\end{tabular}

We present the following article in accordance with the Narrative Review reporting checklist (available at http:// dx.doi.org/10.21037/apm-20-1957).

\section{Diagnosis and severity of the disease}

Acquired AA, resulting from exposure to ionizing radiation, chemicals, drugs with strong myelosuppressive effects, or due to viral infections (e.g., HCV, HIV, herpesviridae), systemic connective tissue disease, blood cancer, thymoma, pregnancy. In most cases, acquired AA is the result of an autoimmune reaction against hematopoietic stem cells (increased cytotoxic activity of $\mathrm{T}$ cells and increased production of cytokines that inhibit hematopoiesis by Th1 cells) and stimulation of apoptosis by the Fas/Fasligand system. Typical for this disease is the impairment of all hematopoietic lines, which in most cases coexists with anemia, leukopenia and thrombocytopenia $(3,4)$.

Diagnosis of AA is based on the detection of pancytopenia in peripheral blood and in bone marrow trepanobioptate atrophy of normal hematopoiesis, without dysplasia. Bone marrow cellularity does not exceed $25 \%$ of age norm. In peripheral blood morphology, mono- or bipenia, erythrocyte macrocytosis, and lymphocyte count within reference limits observed in the early stages of the disease. The severity of AA are classified according to the haematological values (Table 1) (5).

\section{Clinical presentation}

Signs and symptoms depend on the degree of peripheral blood cytopenia. The clinical picture may be dominated by the symptoms of haemorrhagic diathesis related to thrombocytopenia: the presence of characteristic ecchymosis on the skin and a tendency to spontaneously bruise, to bleeding from mucous membranes, bleeding from the nose, from the gums, from the digestive, genital, urinary tract. Patients often have severe atypical infections associated with severe neutropenia. The presence of tonsillitis with the presence of necrotic, ulcerative and aftlike lesions is characteristic. Typical is the lack of response to standard empirical antibiotic therapy. Patients with AA have an increased incidence of severe bacterial and fungal infections (5-7). AA may coexist with nocturnal paroxysmal hemoglobinuria (PNH) or myelodysplastic syndromes (MDS). This relationship may become evident when a patient with AA is observed to have hemolysis or thrombosis or when $\mathrm{PNH}$ is transformed into bone marrow hypoplasia. Abnormal blood cells are thought to initiate an immune response that damages hematopoietic stem cells and other hematopoietic precursors (8-10). In one prospective adult study, the $\mathrm{PNH}$ cell population in peripheral blood (range: $0.5 \%$ to $23.1 \%$ ) accounted for $68 \%$ of 122 patients with newly diagnosed AA (11). Chromosomal abnormalities characteristic of MDS are observed in a smaller number of patients with AA (estimated 5-15\%). Dysplastic hematopoietic stem cells in MDS may undergo immune depletion by $\mathrm{T}$ cells and lead to bone marrow hypoplasia, characteristic of AA. This subgroup of MDS patients presents hypoplastic bone marrow that has some features in common with $\mathrm{AA} / \mathrm{PNH}(12,13)$.

Differential diagnosis of AA also includes other causes of pancytopenia, such as megaloblastic anemia, bone marrow infiltration (myelofibrosis), various cancers, sequestration/ redistribution (hypersplenism), large granular lymphocytic leukemia or acute myeloid leukemia (AML). Physical examination, peripheral blood smear assessment and bone marrow biopsy allow for the diagnosis of these disorders and exclusion of AA, but more specialized tests (cytogenetic or molecular diagnostics) are often required $(5,6)$. 


\section{Managment of patients with AA}

The management of patients with AA depends on the cause and severity of pancytopenia. In patients with acquired AA, the therapeutic strategy is different compared to patients with congenital AA. In current therapy recommendations, its selection depends on the severity of symptoms, the patient's age, the availability of a compatible donor, and comorbidities. For patients under 50 years of age with very severe and severe plastic anemia (VSAA/SAA), allogeneic hematopoietic stem cell transplantation (allo-HSCT) from a matched sibling donor remains standard first-line therapy, while for other patients with VSAA/SAA without a matched sibling donor, immunosuppressive therapy (IST) with antithymocyte globulin (ATG) and cyclosporin A (CsA) using eltrombopag, which has a beneficial effect on treatment outcomes. Appropriate supportive treatment is an integral element of therapy in patients with AA (14-16).

\section{Supportive care}

Patients after IST and allo-HSCT treatment require longterm symptomatic management including platelet cell concentrate and red blood cell concentrate transfusions and treatment of infectious complications. In very elderly people or with moderate pancytopenia, these interventions may be the only therapy used (17). For any patient for alloHSCT, transfusions should be used selectively to reduce the risk of immunization to donor antigens. Blood preparations from siblings or a family donor should be carefully avoided in order to minimize the risk of transplant failure caused by an immune response to donor antigens (18). Basically, lowleukocyte and irradiated products (25-30 Gy dose) are used to reduce, among others risk of febrile post-transfusion reactions, likelihood of alloimmunity, as well as prevention of cytomegalovirus (CMV) infection $(19,20)$.

The indication for the administration of red blood cell concentrate transfusions is a decrease in hemoglobin (HGB) concentration below $6 \mathrm{~g} / \mathrm{dL}$ and prophylactic platelet transfusions should be performed when the patient's platelet count (PLT) drops below $10 \times 10^{9} / \mathrm{L}$. In the presence of concomitant complications, such as fever or bleeding, the PLT number should be maintained $>20 \times 10^{9} / \mathrm{L}$ to reduce the risk of life threatening haemorrhage (21).

\section{Chelating treatment}

Patients with AA who receive multiple red blood cell transfusions are at risk of iron overload and associated organ damage (22). Transfusion of one unit of red blood cell concentrate provides about $150-200 \mathrm{mg}$ of iron, while the daily physiological loss is about $1.5 \mathrm{mg}$. Symptoms of iron storage (secondary hemochromatosis) may occur after transfusion of 10-20 units of red blood cell concentrate. Iron overload is assessed based on serum ferritin, magnetic resonance imaging of the heart and liver, and liver biopsy histopathology. Patients undergoing allo-HSCT or IST who have responded to treatment and demonstrate signs of secondary hemochromatosis can be treated by phlebotomy $(23,24)$. There are no specific guidelines for phlebotomy after allo-HSCT in patients with AA. According to generalny accepted principles, chelating treatment is needed if the ferritin concentration is in the range $1,000-1,500 \mu \mathrm{g} / \mathrm{L}$, which corresponds to the iron content: $7 \mathrm{mg} / \mathrm{g}$ dry weight of liver tissue (25). It should be emphasized that the benefits of chelating therapy in the group of patients with AA are generally unknown and no guidelines for its use are available. The most commonly used drug is deferoxamine (Desferal), administered at an initial dose of approx. Forty $\mathrm{mg} / \mathrm{kg} / 24 \mathrm{~h}$ in long-term (at least $10 \mathrm{~h}$ ) subcutaneous or intravenous drip for 5 days a week. Subcutaneous administration is usually not possible in patients with SAA due to comorbid thrombocytopenia (26). Ferritin levels should be monitored every few weeks and the dose should be adjusted accordingly. Some observations suggest a possible benefit of chelation therapy with deferasirox (Exjade), a chelating drug for oral use. To reduce iron overload, it is used chronically at a dose of $30 \mathrm{mg} / \mathrm{kg} / \mathrm{day}$, and preventively at $20 \mathrm{mg} / \mathrm{kg} /$ day. In a prospective 1 -year study on the evaluation of iron chelation in patients receiving deferasirox (Exjade), its efficacy and safety were assessed in 116 patients with AA.

Median ferritin levels were reduced from 3,254 to $1,854 \mathrm{ng} / \mathrm{mL}$ after 1 year in both untreated and previously treated patients. The decrease in mean alanine aminotransferase over 1 year significantly correlated with the decrease in serum ferritin (27). In another report of 72 AA patients receiving deferasirox, transfusion independence was observed in $46 \%$ of patients with chronic non-severe AA, not undergoing IST therapy, and in $40 \%$ of patients who received concomitant IST. In addition to reducing iron overload, deferasirox had an effect on haematological parameters in some patients with AA (increased PLT and HGB), however, further studies are needed (28). Registered in Europe in 2018, the oral 
chelating drug Deferiprone (Ferriprox) is not recommended in $\mathrm{AA}$, among others due to induction of neutropenia in an unknown mechanism.

\section{Prevention/treatment of infection}

There are no specific guidelines for the prophylactic antibacterial or antifungal treatment of patients with VSAA/SAA. Some experts suggest the use of prophylactic antifungal therapy with voriconazole or posaconazole in individuals with ANC (absolute neutrophil count) $<500$ cells $/ \mu \mathrm{L}$ based on better survival after use in patients after HSCT with acute leukemia $(17,29)$. The use of preventive antibiotic therapy is controversial, its use in some patients reduces mortality, but also increases the risk of drug resistance and causes adverse changes in the intestinal microflora; in addition, some antibacterial drugs myelosuppressive. During lymphopenia after ATG treatment, prevention of pneumonia of the etiology of Pneumocystis jirovecii should be used, choosing an alternative drug for trimethoprim-sulfamethoxazole due to its myelosuppressive effect. Antimicrobial prevention with quinolone antibiotics in patients with VSAA may reduce the risk of Gram-negative sepsis, but routine use of antibiotics in patients with higher neutrophil count not recommended to reduce the development of antibiotic resistance (30). A patient with AA with fever requires immediate hospitalization and treatment without waiting for the results of bacteriological tests. Initially, an aminoglycoside antibiotic is administered in combination with $\beta$-lactam active against Pseudomonas aeruginosa. If the patient has fever for 2 days despite antibiotic therapy, suspected fungal infection and immediately start intravenous antifungal Aspergillus (amphotericin) or voriconazole or caspofungin. Fungal cause should be suspected especially of inflammatory changes in the lungs or sinusitis (31). In the absence of response to antibiotic and antifungal agents, short-term treatment with granulocyte colony-stimulating factor (G-CSF) should be considered. Routine use of G-CSF outside of eutropenic fever episodes is controversial. For patients not responding to anti-infective therapy, a granulocyte concentrate may be used. So far, however, the clear benefits of their use have not been confirmed (32). The benefits and risks of vaccines in AA also remain controversial because of the risk of immune activation, and some AA guidelines do not recommend vaccination except for patients after allo-HSCT. Vaccination efficacy for AA patients also remains controversial due to the risk of immune activation, and some AA guidelines do not recommend vaccination except for patients after allo-HSCT (6).

\section{The role of growth factors}

The concentration of hematopoietic cytokines (growth factors) are quite high in patients with AA and are not generally used as part of routine management. Exceptions include the possibility of using G-CSF in patients with frequent or severe infections, and the use of thrombopoietin receptor agonists (i.e., Eltrombopag) initiating signaling cascades that induce proliferation and differentiation of megakaryocytes from bone marrow progenitor cells. Eltrombopag is recommended for patients with refractory disease, although it is currently also recommended for first-line treatment with IST. In contrast, G-CSF is not a standard therapy in AA. There is no evidence that G-CSF corrects a hematopoietic stem cell defect in AA $(33,34)$. In addition, the use of G-CSF in IST was not associated with an improvement in response or survival rates. Another issue related to G-CSF administration is the fear that it may promote the development or evolution of a clonal cell population with cytogenetic abnormalities or mutations that may predispose the patient to the development of myelodysplasia or AML. The role of G-CSF in clonal evolution (if present) is difficult to determine because patients with acquired AA have an elevated baseline risk of clonal disorders. Similarly, erythropoietin is not used in AA therapy because there are not enough erythropoietic precursor cells in the bone marrow to be effective (35).

\section{Conclusions}

AA is a rare, life-threatening syndrome of bone marrow failure. Transplant-based therapies or IST recommended depending on the severity the disease and the patient's age is crucial but the very important role of supportive treatment should be appreciated. Improved prognosis in patients with $\mathrm{AA}$ is associated with greater effectiveness of supportive therapy. However, there are no clear recommendations. Primarily, appropriate treatment of infections in neutropenic patients should be instituted. Intravenous broad-spectrum antibiotic therapy in combination with antifungal and antiviral agents is recommended. Treatment of severe infections with growth factors such as G-CSF is also useful in AA patients. They provide a transient increase in the number of granulocytes needed to control the infection. Erythropoietin is ineffective, therefore 
the use of its recombinant preparations is not justified. Supportive treatment should also include the transfusion of leukocyte-depleted and irradiated blood components, platelet and red blood cell concentrates, necessary in causally treated patients, and in elderly patients with anemia and thrombocytopenia, in whom aggressive treatment is contraindicated. Multiple blood cell transfusions are associated with iron overload, hence the need to monitor ferritin levels and implement appropriate iron overload treatment. Comprehensive therapy of a patient with AA, taking into account his causal treatment and the necessary supportive treatment, depending on the clinical condition, will guarantee the achievement of therapeutic success.

\section{Acknowledgments}

Funding: None.

\section{Footnote}

Reporting Checklist: The authors have completed the Narrative Review reporting checklist. Available at http:// dx.doi.org/10.21037/apm-20-1957

Conflicts of Interest: All authors have completed the ICMJE uniform disclosure form (available at http://dx.doi. org/10.21037/apm-20-1957). The authors have no conflicts of interest to declare.

Ethical Statement: The authors are accountable for all aspects of the work in ensuring that questions related to the accuracy or integrity of any part of the work are appropriately investigated and resolved.

Open Access Statement: This is an Open Access article distributed in accordance with the Creative Commons Attribution-NonCommercial-NoDerivs 4.0 International License (CC BY-NC-ND 4.0), which permits the noncommercial replication and distribution of the article with the strict proviso that no changes or edits are made and the original work is properly cited (including links to both the formal publication through the relevant DOI and the license). See: https://creativecommons.org/licenses/by-nc-nd/4.0/.

\section{References}

1. Fan R, Wang W, Wang XQ, et al. Incidence of adult acquired severe aplastic anemia was not increased in
Shanghai, China. Ann Hematol 2011;90:1239-40.

2. Akram Z, Ahmed P, Kajigaya S, et al. Epidemiological, clinical and genetic characterization of aplastic anemia patients in Pakistan. Ann Hematol 2019;98:301-12.

3. Shimamura A. Aplastic anemia and clonal evolution: germ line and somatic genetics. Hematology Am Soc Hematol Educ Program 2016;2016:74-82.

4. Yamazaki H. Acquired aplastic anemia: recent advances in pathophysiology and treatment. Rinsho Ketsueki 2018;59:711-5.

5. Dolberg OJ, Levy Y. Idiopathic aplastic anemia: diagnosis and classification. Autoimmun Rev 2014;13:569-73.

6. Killick SB, Bown N, Cavenagh J, et al. Guidelines for the diagnosis and management of adult aplastic anaemia. $\mathrm{Br} \mathrm{J}$ Haematol 2016;172:187-207.

7. Young NS, Kaufman DW. The epidemiology of acquired aplastic anemia. Haematologica 2008;93:489-92.

8. Risitano AM, Bruno Rotoli B. Paroxysmal nocturnal hemoglobinuria: pathophysiology, natural history and treatment options in the era of biological agents. Biologics 2008;2:205-22.

9. Sugimori C, Mochizuki K, Qi Z, et al. Origin and fate of blood cells deficient in glycosylphosphatidylinositolanchored protein among patients with bone marrow filure. Br J Haematol 2009;147:102-12.

10. Maciejewski JP, Rivera C, Kook H,et al. Relationship between bone marrow failure syndromes and the presence of glycophosphatidyl inositol-anchored protein-deficient clones. Br J Haematol 2001;115:1015-22.

11. Sugimori C, Chuhjo T, Feng X, et al. Minor population of CD55-CD59- blood cells predicts response to immunosuppressive therapy and prognosis in patients with aplastic anemia. Blood 2006;107:1308-14.

12. Ogawa S. Clonal hematopoiesis in acquired aplastic anemia. Blood 2016;128:337-47.

13. Wlodarski MW, Gondek LP, Nearman ZP, et.al. Molecular strategies for detection and quantitation of clonal cytotoxic T-cell responses in aplastic anemia and myelodysplastic syndrome. Blood 2006;108:2632-41.

14. Desmond R, Townsley DM, Dunbar C, et al. Eltrombopag in aplastic anemia. Semin Hematol 2015;52:31-7.

15. Townsley DM, Scheinberg P, Winkler T, et al. Eltrombopag added to standard immunosuppression for aplastic anemia. N Engl J Med 2017;376:1540-50.

16. Yoshida N, Kobayashi R, Yabe H, et al. First-line treatment for severe aplastic anemia in children: bone marrow transplantation from a matched family donor versus immunosuppressive therapy. Haematologica 
2014;99:1784-91.

17. Höchsmann B, Moicean A, Risitano A, et al. Supportive care in severe and very severe aplastic anemia. Bone Marrow Transplant 2013;48:168-73.

18. Champlin RE, Horowitz MM, van Bekkum DW, et al. Graft failure following bone marrow transplantation for severe aplastic anemia: risk factors and treatment results. Blood 1989;73:606-13.

19. Fast LD. Developments in the prevention of transfusionassociated graft-versus-host disease. Br J Haematol 2012;158;563-8.

20. Dzik WH. Leucoredution of blood components. Curr Opin Hematol 2002;9:521-6.

21. British Committee for Standards in Haematology, Blood Transfusion Task Force. Guidelines for the use of platelet transfusions. Br J Haematol 2003;122:10-23.

22. Takatoku M, Uchiyama T, Okamoto S, et al. Retrospective nationwide survey of Japanese patients with transfusiondependent MDS or aplastic anemia highlights the negative impact of iron overload on morbidity/mortality. Eur J Haematol 2007;78:487-94.

23. Pullarkat V, Blanchard S, Tegtmeier B, et al. Iron overload adversely affects outcome of allogeneic hematopoietic cell transplantation. Bone Marrow Transplant 2008;42:799-805.

24. Majhail NS, Lazarus HM, Burnd LJ. Iron overload on hematopoietic cell transplantation. Bone Marrow Transplant 2008;41:997-1003.

25. Marsh JC, Ball SE, Cavenagh J, et al. Guidelines for the diagnosis and management of aplastic anemia. Br J Haematol 2009;147:43-70.

26. Gattermann N. The treatment of secondary hemochromatosis. Dtsch Arztebl Int 2009;106:499-504, I.

27. Lee JW, Yoon SS, Shen ZX, et al. Iron chelation therapy with deferasirox in patients with aplastic anemia: a

Cite this article as: Urbanowicz I, Nahaczewska W, Celuch B. Narrative review of aplastic anemia - the importance of supportive treatment. Ann Palliat Med 2021;10(1):694-699. doi: 10.21037/apm-20-1957 subgroup analysis of 116 patients from the EPIC trial. Blood 2010;116:2448-54.

28. Lee JW, Yoon SS, Shen ZX, et al. Hematologic responses in patients with aplastic anemia treated with deferasirox: a post hoc analysis from the EPIC study. Haematologica 2013;98:1045-8.

29. Robenshtok E, Gafter-Gvili A, Goldberg E. et al. Antifungal prophylaxis in cancer patients after chemotherapy or hematopoietic stem-cell transplantation: systematic review and meta-analysis. J Clin Oncol 2007;25:5471-89.

30. Gafter-Gvili A, Fraser A, Paul M, et al. Meta-analysis: antibiotic prophylaxis reduces mortality in neutropenic patients. Ann Intern Med 2005;142:979-95.

31. Sułek K. Niedokrwistość w przebiegu niewydolności szpiku kostnego. Wielka Interna. Hematologia red. Dmoszyńska A. Medical Tribune, 2011.

32. Quillen K, Wong E, Scheinberg P, et al. Granulocyte transfusions in severe aplastic anemia: an eleven-year experience. Haematologica 2009;94:1661-8.

33. Teramura M, Kimura A, Iwase S, et.al. Treatment of severe aplastic anemia with antithymocyte globulin and cyclosporin A with or without G-CSF in adults: a multicenter randomized study in Japan. Blood 2007;110:1756-61.

34. Tichelli A, Schrezenmeier H, Socie G, et al. A randomized controlled study in patients with newly diagnosed severe aplastic anemia receiving antithymocyte globulin (ATG), cyclosporine, with or without G-CSF: a study of the SAA Working Party of the European Group for Blood and Marrow Transplantation. Blood 2011;117:4434-41.

35. Gurion R, Gafter-Gvili A, Paul M. et al. Hematopoietic growth factors in aplastic anemia patients treated with immunosuppressive therapy--systematic review and meta297 analysis. Haematologica 2009;94:712-9. 